\title{
COMMENTARIES
}

Pages $63-68$

\section{Foci of High Infant Mortality}

M obstetric; pediatric-contribute to the health and survival status of newborn infants; and over the years the United States has been proud of its ability to clemonstrate a steady decline in infant mortality rates. That over 97 per cent of our live births now take place in hospitals and related institutions is proudly cited as one of our more notable community health achievements.

Nevertheless, it is disquieting to read in a recent Public Health Service publication ${ }^{2}$ that in 1964 the infant mortality rate in the United States was twice as high as that described for Swedena dramatic difference. Sweden reported a rate of 14.2 per 1.000 population for that year, followed in order by the Netherlands (14.8), Norway (16.4), Denmark (18.7), England and Wales (19.9), Scotland (24.0) and the United States (24.8).

The immediate reaction of the reader to the apparent magnitude of this rate differential is to raise the question: Are the same kinds of data (entities) being compared? And, after close reading of this report it is obvious that an absolutely literal transcomparison of these rates is not appropriate. Even though national laws governing compulsory registration of vital events in Denmark, Norway and Sweden date back to the 15 th century, the uniform definitions and registration practices necessary for valid international comparisons are yet to be achieved. Sweden, for example, did not adopt the WHO definition of "live birth" until 1959; and Denmark still has no legal definition of "signs of life."

Since 1935 the seven countries included in this report have demonstrated a 55 to 72 per cent reduction in infant mortality rates, with the greatest rates of decline occurring in the 1930's and $1940^{\circ}$ s. In the United States, however, the rate of decine since 1950 has been much less than that recorded in other countries, a phenomenon which cannot be dismissed simply as a reflection of different ways of keeping vital statistics.

A better understanding of the circumstances contributing to fetal and infant mortality of a country can be gained by analysis of the demographic characteristics of its population. Chapter $\mathrm{V}$ of this report, "Associated Demographic Fac- tors," reviews these important considerations, though comparisons of socioeconomie differences of these countries are only touched on. More information on this significant variable would provide a better basis for appreciation of the true differences in mortality experience. For instance. how does the United States compare socioeconomically with these six. Western European countries? Are socioeconomic conditions homogeneous or heterogeneous within each country? Do these countries have large "pockets of poverty," as are found in our urban slums, appalachia, and anong the poor white and colored of our Southy

In the "Discussion" that follows this chapter, the author concludes that: "Examination of all these demographic characteristics (geographic variation, color, sex, maternal age and parity, low birth weight, previous loss. socioeconomic level and illegitimacy) does not identify any single characteristic which completely explains the variations in mortality." " Such an approach is simplistic and misleading. What need is there to find a single characteristic which may be responsible for such a complex and extreme reaction as death? Unfavorable demographic conditions rarely occur in isolation. As Robert Straus, of the University of Kentucky Medical School, states in his discussion of the barriers to health progress that confront the rural poor: "The health status of our rural poor clearly illustrates the frequently demonstrated tendency for many forms of human pathology to occur simultaneously. . . . It is seen in the clustering of such problems as unemployment, undereducation, inadequate housing, delinquency, marital inconpatibilisy, alcoholism, poverty and poor health." 3

Infant, Fetal and Maternal Mortality, United States-1963, a companion Public Health Service

\begin{tabular}{cccc}
\multicolumn{4}{c}{$\begin{array}{c}\text { Binh Occurring Onlside of Hospitals } \\
\text { Per Cent of Total Births-1963 }\end{array}$} \\
\hline & White & Nonwhite & Total \\
\hline United States & 0.9 & 12.1 & 2.6 \\
Nississippi & 0.9 & 47.6 & 25.7 \\
\hline
\end{tabular}




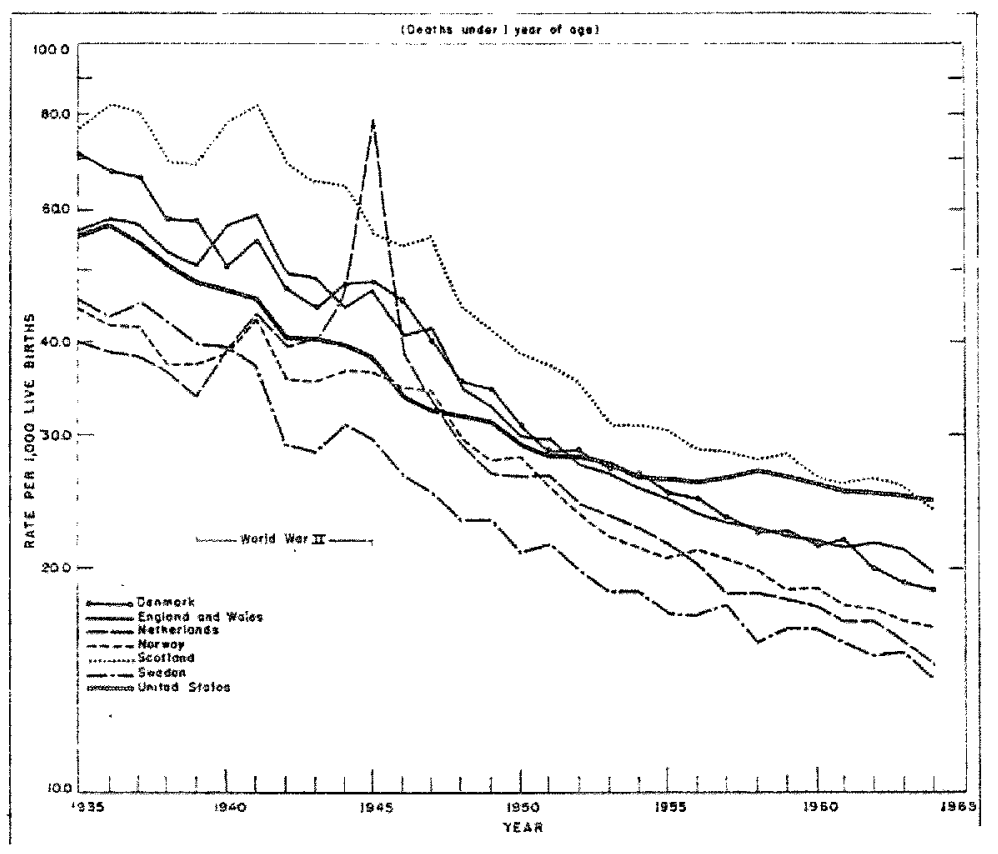

FIC. 1. Infant mortality rates: selected countries, 1935-1964. (From PHS Publication No. 1,000-Series 3-No. 6, March 1967.)

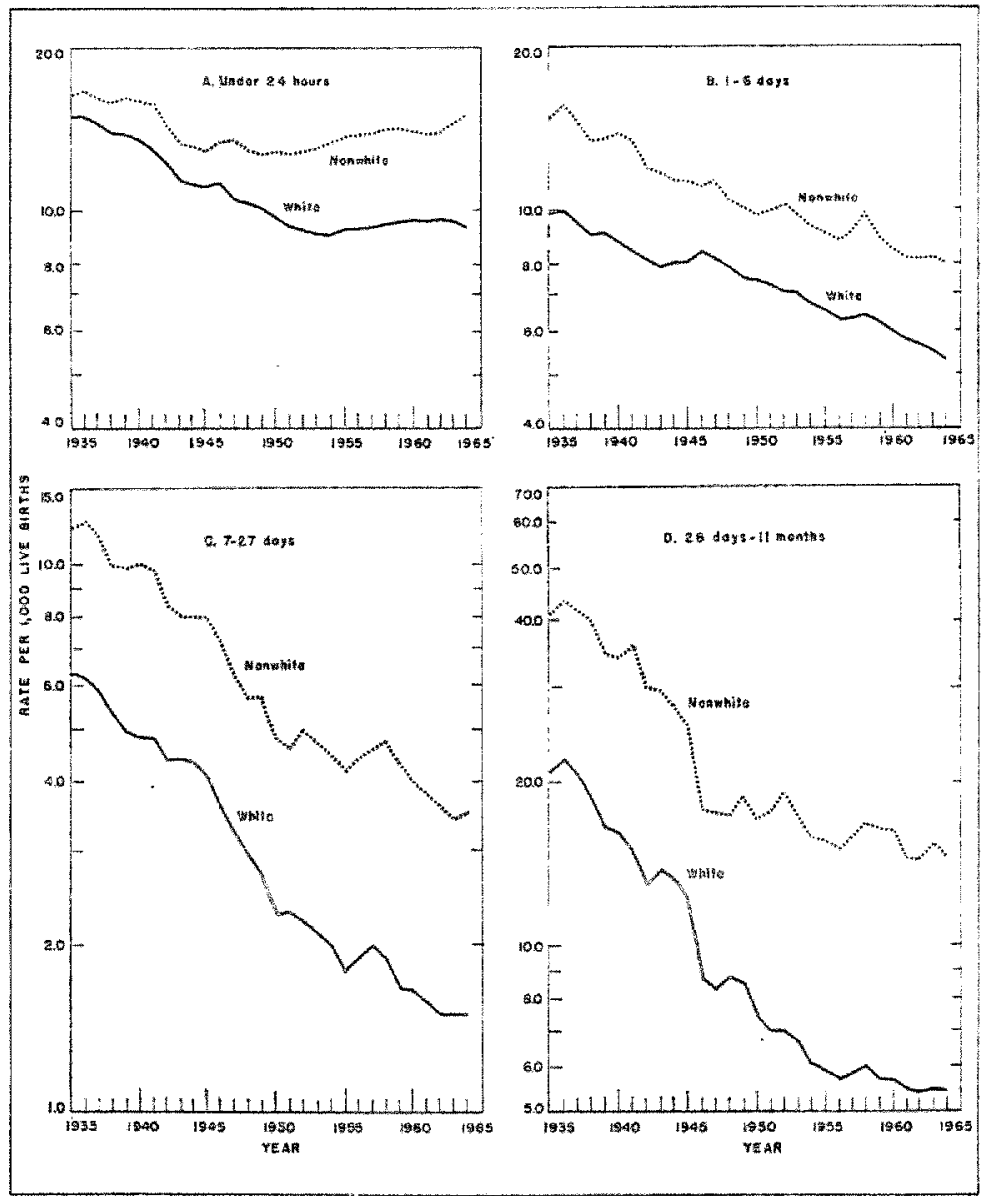

Fic. 2. Infant mortality rates by color and age at death: United States, 1935-1964. (From PHS Publication No. 1,000-Series $20-$ No. 3 , September 1966.) 
publication, makes clearly conspicuous the tragic background of the high infant mortality rates in this country. Many of these deaths are preventable without the need for advances in medical science. For example, in 1963 the mortality rates for white infants ranged from 18.2 in Utah up to 28.3 in Nevada; whereas for nonwhite infants, the range was from 21.3 in Oregon to 56.2 in Arizona and to 57.6 in Mississippi. The comparatively high rates observed in Arizona is related to the Indians and that in Mississippi is related to the Negroes.

The rate of hospitalization for delivery, another component of better medical care in the United States, demonstrates unnecessarily large geographic variation. Mississippi has a relatively low rate of hospitalization for obstetric care for nonwhites as compared with the United States as a whole:

Medical experts look upon the infant mortality rate as a valid index of the level of health within a community. High rates tend to be associated with such unfavorable conditions as low socioeconomic conditions, poor environmental health, limited medical facilities and resources, and poor provision or low utilization of prenatal care be. fore delivery.
Maternal and child health programs authorized under the provisions of Title $V$ of the 1935 Social Security Act and sponsored by the individual states with the financial assistance from the Federal Government have been in operation for many years; yet these programs still need much encouragement and expansion in those states where the infant mortality rates are much higher than elsewhere.-Eoward A. DUFFY, M.P.H., Research Associate, Maternal and Child Health, University of Michigan, Ann Arbor, Michigan 48108.

\section{References}

1. International Comparison of Perinatal and Infant Mortality: the United States and Six West European Countries. PFS Publication No. 1,000 -Series 3-No. 6. March 1967.

2. Infant, Fetal and Maternal Mortality, United States -1963. PHS Publication No. 1,000-Series 20No. 3, September 1966.

3. Infant Mortality: a Challenge to the Nation. Children's Bureau, Dept. of Health, Education and Welfare, 1966.

4. Straus, Robert: Poverty as an Obstacle to Health Progress in Our Rural Areas. Amer. J. Public Health 55: No. 11, pp. 1772 -1779, November 1965.

\section{National Blueprint for Public Welfare}

In 1964 the Secretary of Health, Education and Welfare, under Congressional directive, set up an "Advisory Council on Public Welfare," with instructions to survey federally-aided public assistance and child welfare programs for the purpose of proposing ways to make them more responsive to the problems which change with changing social and economic circumstances. The considerations and recommendations of this Council contain many constructive suggestions for the full application of public welfare potentials to many of the Nation's social problems. The suggestions here extracted are those of particular pertinence to social service problems of children and adolescents.

\section{Need for Improved Public Welfare Measures}

General prosperity will not raise the near ffth. of the population now living in poverty to even a minimal level of living. Many of the economic measures which are of benefit to most Americans will have little or no effect upon those at the bottom of the economic ladder.

\section{NATIONAL BLUEPRINT FOR PUBLIC WELFARE}

Major Program Recommendations of the Advisory Council on Public Welfare, June 1966

- A national minimum standard for public assistance payments below which no State may fall

- A nationwide comprehensive program of public assistance based upon a single criterion: Need

- A unitorm, simple plan for Eederal-State sharing in costs of all public welfare programs which provides for equitable and reasonable fiscal effort among States, and recogrizes the relative fiscal capacity of the Tecieral and State Governments

- Comprehensive social services readily accessible, as a right, at all times to all who need them

- All welfare programs receiving Federal funds to be administered consistent with the principle of public welfare as a right 